\title{
Cardiac Rehabilitation in Coronary Artery Disease: A Clinical Study to Assess its Effect on Comorbid Depressive Symptoms
}

\author{
Saeed Shoja Shafti*1 and Masuod Ahmadie ${ }^{2}$ \\ ${ }^{1}$ Professor of Psychiatry, University of Social Welfare and Rehabilitation Sciences (USWR), Razi Psychiatric Hospital, Iran \\ ${ }^{2}$ Cardiologist, Iran
}

*Corresponding author: Saeed Shoja Shafti MD, University of Social Welfare and Rehabilitation Sciences (USWR), Razi Psychiatric Hospital, Iran

\section{ARTICLE INFO}

Received: 慧 March 19, 2019

Published: March 25, 2019

Citation: Saeed Shoja Shafti, Masuod Ahmadie. Cardiac Rehabilitation in Coronary Artery Disease: A Clinical Study to Assess its Effect on Comorbid Depressive Symptoms. Biomed J Sci \& Tech Res 16(3)-2019. BJSTR. MS.ID.002842.

\section{ABSTRACT}

Introduction: The high prevalence of co-morbidly among cardiac patients may result in undesired consequences, which certainly can compromise their managements. Cardiac rehabilitation can be an appropriate adjunctive intervention for amelioration of such morbid processes.

Method and Materials: An open comparative study had been performed between a group of ischemic cardiac patients with depressive symptoms, who received cardiac rehabilitation programs, in addition to their standard treatments $(n=30)$, in comparison with a similar group of ischemic patients who had received only the customary managements $(\mathrm{n}=30)$.

Results: Significantly, more patients in the target group (56.6\%) gained benefit from cardiac rehabilitation, in comparison with only $30 \%$ of them in the control group $(\mathrm{P}<0.05)$.

Conclusion: Cardiac rehabilitation seems to be a valuable method for enhancement of improvement in depressed ischemic heart patients.

\section{Introduction}

Cardiac rehabilitation, as one of the known tactics for functional restoration of cardiac functions, according to some studies may have important healing or preventive effects with respect to psychiatric problems, like depression or anxiety, in patients who have suffered cardiovascular accidents. Psychiatric problems can exacerbate cardiovascular dysfunction a number of mechanisms $[1,2]$. For example, in depressive patients, the somatization of symptoms can reinforce the somatic complaints of ischemic heart patients or, alternately, by reducing the secretion of beta-endorphin the chest pain and its severity can really be increased [2]. Noncompliance with diet and prescribed medications [3], disturbed relationship with caretaker, imposed unnecessary restriction in social and occupational activities due to cognitive distortions or psychomotor retardation, sleep problems, irritability or agitation with its dangerous homodynamic sequels, lowered threshold and vulnerability to cardiovascular accidents due to arrhythmias and decreased sympathetic and increased parasympathetic activity, stress induced coronary vasospasm and platelet aggregation due to increased epinephrine and decreased substance P, are among the major sequels of depression, which has a life-time prevalence of $26 \%$ among ischemic cardiac patients [1]. In a prevalence survey in Tehran, there was a high rate of psychiatric co-morbidity (64\%) among 101 ischemic heart patients who had been admitted in the Coronary Care Unit (CCU) of an academic general hospital [4].

All of those psychiatric problems had been started many months or years before admission in the CCU. $42.57 \%$ of them had co-morbid depression, $9.90 \%$ had an anxiety disorder, and $10.89 \%$ were suffering from Not Otherwise Specified (NOS) problems. 
According to the findings of that study, integration of psychiatric co-morbidity and biological risk factors (hypertension, diabetes mellitus, cigarette smoking, and hyperlipidemia) could increase the risk of cardiac events up to three folds [4]. In general, by considering the additional risk (16-20\%) of occurrence of major depressive disorder after myocardial infarction (half of them show depressive symptoms 3 months after infarction) with its fivefold increase in mortality in the next six months, we can understand the importance of psychiatric co-morbidity in coronary artery disease. Even hopelessness as a single symptom in depression, disregard to other symptoms, increase the risk of morbidity 1.5-2.5 fold [1]. Moreover, three community-based studies have shown a significant relationship between anxiety disorders and sudden cardiac death.

One study of 1,457 male subjects followed up over 6 years found the risk of cardiac-related death elevated almost fourfold in those with phobic anxiety [5]. Acutely stressful events, as well, dramatically increase cardiac morbidity and mortality. In a prospective study of 95,647 Finnish men and women, the risk of all-cause mortality in the first week following spousal death was two times normal. The risk of any ischemic heart disease event in that period was elevated 2.3-fold in men and 3.5-fold in women, an effect independent of age [6]. Finally, regarding relationship between Type A Behavior Pattern (TABP)-time urgency, hostility, and achievement-striving-competitiveness-and the risk of coronary heart disease, while a 1987 meta-analysis documented the weakening of the association of type A behavior with coronary heart disease [7], the controversies still go on [8-10]. Therefore, cardiac rehabilitation with its supportive, cognitive and behavioral aspects seems to have important psychotherapeutic benefit in accompany with other standard treatments. In this research we evaluated the efficacy of cardiac rehabilitation on amelioration of depressive symptoms.

\section{Methods and Materials}

In an open trial, 30 randomly chosen patients, among referred ones to a cardiac rehabilitation center with the history of a recent myocardial infarction (in the last month), who were suffering from co-morbid depression, too (Table 1), had been delivered a rehabilitation program including:

Table 1: Inclusion and exclusion criteria for selecting patients.

\begin{tabular}{|c|c|}
\hline INCLUSION CRITERIA & EXCLUSION CRITERIA \\
\hline $\begin{array}{l}\text { Ischemic heart patients with } \\
\text { myocardial infarction in the last } \\
\text { month, plus co-morbid depression, } \\
\text { which have been started no less } \\
\text { than one month before cardiac } \\
\text { event. }\end{array}$ & $\begin{array}{l}\text { 1- Non-ischemic cardiac patients. } \\
\text { 2- Ischemic cardiac patients } \\
\text { without depression. } \\
\text { 3- Ischemic cardiac patients } \\
\text { without myocardial infarction. } \\
\text { 4- Infarction more than one month } \\
\text { ago. } \\
\text { 5- Depression shorter than one } \\
\text { month before infarction. }\end{array}$ \\
\hline
\end{tabular}

a) Explanation of the nature of cardiovascular diseases

b) Description of the essential process of management

c) Recommendations for taking necessary steps for dealing with existing risk factors and stresses (stress management), and

d) Appropriate exercises according to the patient's compliance with accentuation on restoring the ambulatory status and functional activities as soon as possible after aforesaid cardiac event, in addition to their standard treatments.

All of these programs had been accomplished by the rehabilitation team, including cardiologist (head of team), psychiatrist, psychologist, registered nurse and physiotherapist. The program had been accomplished on cardiac patients, out-patiently, within four weeks of being discharged from the hospital, and the session, as well, had been performed once per week (30-45 minutes), for duration of eight weeks per patient. The diagnosis of depression in both groups had been certified by a psychiatrist according to the DSM IV-TR criteria and had been scored by Hamilton Rating Scale for Depression (HRS-D) [11] at the beginning of the program and then every two weeks during the trial. The HRS-D (HAM-D) is an observer-rated scale consisting of 17 to 21 items. Rating is made on the basis of the clinical interview, plus any additional available information by other resources such as staff or family members. The items are rated on either a 0 to $4(0=$ none/absent and $4=$ most severe) or a 0 to 2 spectrum ( $0=$ absent/none and $2=$ severe). Depressed Mood, Feelings of Guilt, Suicide, Insomnia, activities, retardation, agitation, anxiety psychic, anxiety somatic, hypochondriasis, changes of weight, insight, diurnal variation, depersonalization and derealization, paranoid ideations, and obsessive or compulsive symptoms are the items which are scored in HRS-D. The control group, too, included 30 randomly chosen ischemic cardiac patients with similar co-morbid psychopathology, among the referred ones, who received only the standard treatments (antihypertensive, anti-angina, and antidepressant medications). All of the aforesaid patients in both groups had been prescribed antidepressants from no less than one month before their entrance into the trial. Total duration of study was around eighteen months, from August of 2000 till February of 2002.

\section{Statistical Analysis}

Patients were compared on baseline characteristics by means of t-tests. Treatment efficacy also was analyzed by 'Comparison of Proportions'. Statistical significance was defined as a 2-sided $\mathrm{p}$ value $<$ or $=$ to 0.05. MedCalc, version 9.4.1.0, was used as statistical software tool for analysis.

\section{Results}

According to data, the age of the patients in the target group was between 34 and 73 (mean=51.46 \pm 8.56) years old and all of them were male. Duration of their ischemic heart disease was between one month and 24 years (mean=11.35 \pm 2.79 years). 
These parameters in the control group were 31 to 66 (mean $=49.88$ \pm 9.31 ) years old and one month up to 19 years (mean $=10.54 \pm 4.16$ years) respectively, and all of them were male, too. 'Comparison of means' did not show any significant difference with respect to age $(t=0.684, \mathrm{P}<0.49, \mathrm{CI}=-3.04,6.20)$ or duration of ischemic illness $(\mathrm{t}=0.886, \mathrm{P}<0.37, \mathrm{CI}=-1.03,2.65)$ between two groups. According to the scores of HRS-D their depression had been classified into three groups as follows: Mild (10-13), Mild to Moderate (14-17), and Moderate to Severe (>17) (Table 2) (Figure 1). $56.6 \%(n=17)$ of the patients in the target group and $30 \%(n=9)$ of them in the control group showed some improvement in some or most of their sub-scales. 'Comparison of Proportions' showed a significant difference with respect to response to the aforesaid rehabilitation program between two groups $(\mathrm{z}=2.08$, $\mathrm{p}$-value $<0.03$, CI $95 \%=$ $0.015,0.517)$. The items which exhibited the most influence, in this regard, in the target group were: depressed mood (2 to 1 or 1 to 0 ), work and activities ( 1 to 0 ), helplessness ( 2 to 1 or 1 to 0 ), hopelessness ( 2 to 1 or 1 to 0 ), anxiety psychic ( 1 to 0 ), and hypochondriasis ( 2 to 1 or 1 to 0 ) in $20 \%, 20 \%, 23.33 \%, 26.66 \%$, $36.67 \%$ and finally $23.33 \%$ of the patients, respectively.

Table 2: Classification of patients according to the severity of depression.

\begin{tabular}{|c|c|c|c|c|}
\hline Outcome measure (HRS-D) Group & $\begin{array}{c}\text { Mild } \\
(10-13)\end{array}$ & $\begin{array}{l}\text { Mild to Moderate } \\
\qquad(14-17)\end{array}$ & $\begin{array}{l}\text { Moderate to Severe } \\
\qquad(>17) s s s\end{array}$ & Total \\
\hline Target & $17(56.67 \%)$ & $8(26.67 \%)$ & $5(16.67 \%)$ & $30(100 \%)$ \\
\hline Control & $14(46.67 \%)$ & $10(33.33 \%)$ & $6(20 \%)$ & $30(100 \%)$ \\
\hline
\end{tabular}

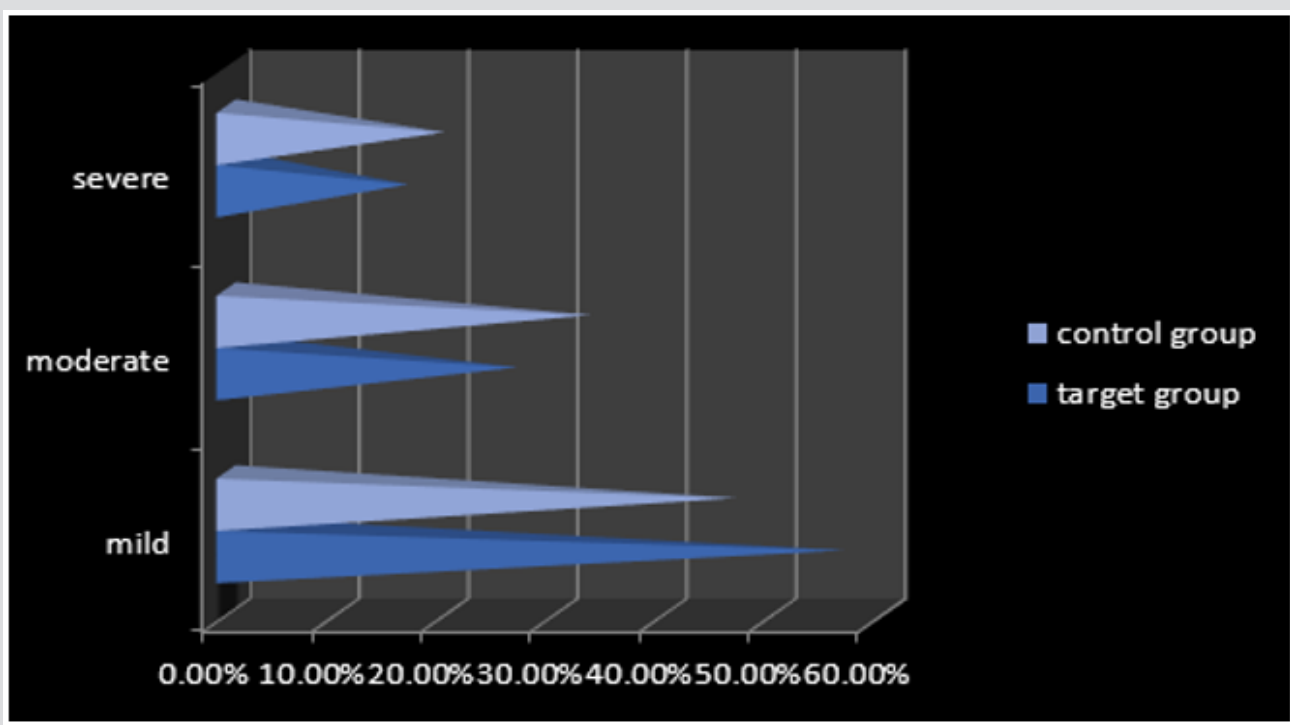

Figure 1: Severity of depressive symptoms in both groups at baseline.

Psychic anxiety was the most influenced one in the target group (Table 3). Most improvements had appeared in the last two months. No important improvement was evident in the remaining items. Besides, all of these positive responses had been palpable in the Mild and Mild to Moderate classes of that group. In the control group, too, there were some improvements in the depressed mood (16.66\%), work activities (10\%), helplessness (10\%), hopelessness

Table 3: Physiognomies of improved symptoms in the target group.
(10\%), anxiety psychic (16.66\%), hypochondriasis (10\%), agitation (10\%), and retardation (6.66\%). The psychic anxiety and depressed mood also were the items with the greatest improvement in the control group (Table 4), which had appeared mostly in the last ten weeks of the trial among the first two classes of the patients (Figure 2).

\begin{tabular}{|c|c|c|c|c|c|c|}
\hline $\begin{array}{c}\text { HRS-D ITEMS } \\
\text { Patients }\end{array}$ & $\begin{array}{c}\text { Depressed } \\
\text { Mood } \\
\text { (2to1-1to0) }\end{array}$ & $\begin{array}{c}\text { Work } \\
\text { Activities } \\
(1 \text { to0) }\end{array}$ & $\begin{array}{c}\text { Helplessness } \\
\text { (2to1-1to0) }\end{array}$ & $\begin{array}{c}\text { Hopelessness } \\
\text { (2to1-1to0) }\end{array}$ & $\begin{array}{c}\text { Anxiety } \\
\text { Psychic } \\
\text { (1to0) }\end{array}$ & $\begin{array}{c}\text { Hypochondriasis } \\
\text { (2to1-1to0) }\end{array}$ \\
\hline 1 & + & + & + & + & + \\
\hline 2 & + & + & + & + & + \\
\hline
\end{tabular}




\begin{tabular}{|c|c|c|c|c|c|c|}
\hline 4 & & & + & + & + & \\
\hline 5 & & & + & + & + & \\
\hline 6 & + & & + & + & + & \\
\hline 7 & & + & & & & + \\
\hline 8 & & + & & & & \\
\hline 9 & & & & & + & \\
\hline 10 & + & & & + & + & \\
\hline 11 & & & & & + & + \\
\hline 12 & + & & + & + & & \\
\hline 13 & & & & & + & \\
\hline 14 & & & & & + & + \\
\hline 15 & + & & & & + & + \\
\hline 16 & & & + & + & + & \\
\hline 17 & & + & & & & + \\
\hline Total & 6 & 6 & 7 & 8 & 11 & 7 \\
\hline
\end{tabular}

Table 4: Physiognomies of improved symptoms in the control group.

\begin{tabular}{|c|c|c|c|c|c|c|c|c|}
\hline $\begin{array}{l}\text { HRS-D items } \\
\text { Patients }\end{array}$ & $\begin{array}{c}\text { Depressed } \\
\text { mood (2to1- } \\
1 \text { to0) }\end{array}$ & $\begin{array}{c}\text { Work } \\
\text { Activities } \\
\text { (1to0) }\end{array}$ & $\begin{array}{c}\text { Helpless- } \\
\text { ness (2to1- } \\
\text { 1to0) }\end{array}$ & $\begin{array}{l}\text { Hopelessness } \\
\text { (2to1-1to0) }\end{array}$ & $\begin{array}{l}\text { Anxiety Psy- } \\
\text { chic (1to0) }\end{array}$ & $\begin{array}{l}\text { Hypochodri- } \\
\text { asis (2to1- } \\
\text { 1to0) }\end{array}$ & $\begin{array}{l}\text { Agita- } \\
\text { tion } \\
(1 \text { to0) }\end{array}$ & $\begin{array}{l}\text { Retarda- } \\
\text { tion (1to0) }\end{array}$ \\
\hline 1 & + & + & + & + & + & & + & + \\
\hline 2 & + & & & & + & & + & \\
\hline 3 & & & + & + & & + & & \\
\hline 4 & + & + & & & + & & & \\
\hline 5 & & & + & + & & & & \\
\hline 6 & & & & & & + & + & \\
\hline 7 & & + & & & + & & & + \\
\hline 8 & + & & & & + & & & \\
\hline 9 & + & & & & & + & & \\
\hline Total & 5 & 3 & 3 & 3 & 5 & 3 & 3 & 2 \\
\hline
\end{tabular}

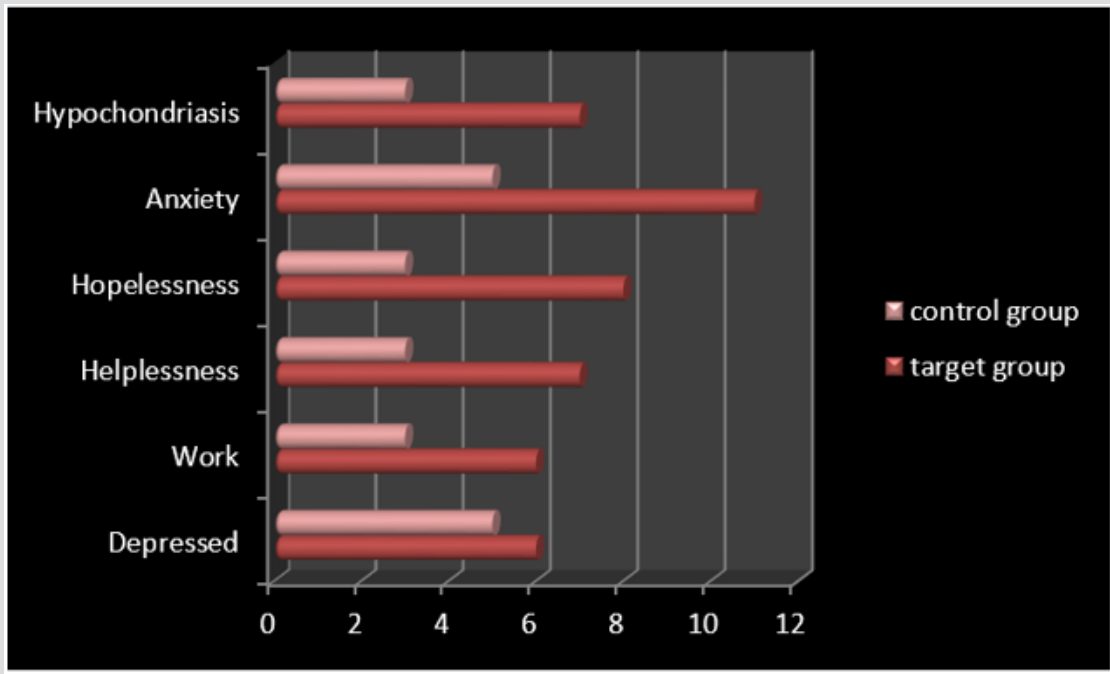

Figure 2: Quantitative difference between groups regarding improvement of HRS-D at the end of assessment. 


\section{Discussion}

Anxiety and depression are more prevalent in patients with cardiovascular disease than in the general population [12]. A study of 200 patients who had suffered a first Myocardial Infarction (MI) found a 1-year cumulative incidence of depression of 25\% [13]. Also, in patients with Congestive Heart Failure (CHF), three studies have found the prevalence of depression to be approximately $20 \%$ [14]. Although the epidemiology of anxiety disorders in CAD is not as well studied as that of depression, the incidence of anxiety symptoms in patients with acute coronary disease in cardiac care units is approximately $50 \%$ [15]. Besides, depression is linked to a large number of major risk factors for CAD or cardiac-related mortality, including cigarette smoking, diabetes, and obesity. Prospective studies indicate that depression is an independent risk factor in the development of these behaviors or conditions and also strong independent risk factor for the development of cardiovascular disease, of acute coronary events, and of mortality from cardiac illness. In general, studies show that the relative risk of incident cardiac disease in healthy individuals with depression or symptoms of depression is about 1.5 to 2 , depending on which cardiac endpoint is used $[16,17]$. Also, findings of a recent study on 2,111 incident myocardial infarctions, in a large Norwegian population based cohort, showed that self-reported symptoms of depression and anxiety, especially if recurrent, were moderately associated with the risk of acute myocardial infarction [18].

Though there was not any substantial wide-ranging reduction in HRS-D in the target group and, likewise, there was not any improvement with respect to severe symptoms, and over again all of the positive responses were slight (1-0 or 2-1), nevertheless the better response of depressive symptoms in the target group in comparison with the control one, which was evident significantly in 'comparison of proportions', had revealed an adjunctive remedial influence of cardiac rehabilitation on this group of cardiac patients; an outcome similar to the findings of Lavie et al. [19-22]. But while methodology of most of the said scholars addressed mainly post-MI mood problems (in contrary to present study which had targeted premorbid mood difficulties just before occurrence of cardiac event), but according to the findings of the current try-out its assistance seems to be generalizable to co-morbid psychiatric symptoms regardless to its primary or secondary process. Moreover, it should not be disregarded that many of the depressive symptoms which appear after such serious events are merely adjustment disorder, not a full-blown major depressive disorder. Therefore, while negative cognitive processing of cardiac patients can be strengthened by the influence of depressive mood and, consecutively, reinforcement of somatic problems and deterioration of their survival, cardiac rehabilitation may decline this negative process by its verbal (explanatory) and nonverbal (physiotherapeutic) components and increase patient's self-esteem and self-competency, which are antagonist of self-depreciation and pessimistic point of view [23].
Several studies have reported improvement in psychological stress in patients with coronary heart disease who have attended cardiac rehabilitation: one recent US observational study of a number of patients with heart failure (left ventricular ejection fraction $<45 \%$ ) reported a decrease in symptoms of depression by $40 \%$ after exercise training cardiac rehabilitation [20]. Also depressed patients who completed their cardiac rehabilitation had a 59\% lower mortality compared with depressed dropout patients who did not undergo cardiac rehabilitation [20]. So, cardiac rehabilitation seems to be a fair adjuvant therapeutic approach which, from a psychotherapeutic standpoint, can decrease the negative cognitive distortion resulting from the depression, comorbid with ischemic heart disease, and in consequence increase therapeutic compliance by its health promoting effect [24]. Small sample size, short duration of trial and gender-based sampling were among the weaknesses of the current assessment. Certainly, further methodical studies in future, with greater sample and longer duration, will prove more vividly various advantageous of this method in cardiac patients with psychiatric co-morbidity.

\section{Conclusion}

Psychiatric symptoms are not infrequent among ischemic cardiac patients (especially depressive illnesses) and can have a detrimental influence on exacerbation of cardiac events by bringing out a morbid circle, incidentally. Its positive influence on psychological manifestations of depression, especially: anxiety, hopelessness, helplessness, hypochondriasis, depressed mood and finally work activities may be accounted as significant remedial effect, because any kind of undesirable impact due to their negative cognitive and somatic influence possibly will jeopardize patient's survival.

\section{Acknowledgment}

The author gratefully acknowledges dear colleagues, Ghiasvand B (MD), Akbari S (MD), and Dadras P (PhD) for their valuable assistance and care.

\section{References}

1. Wayne Katon, Mark Sulivan (1995) Comprehensive textbook of psychiatry: Cardiovascular disorders 6: 1491-1510.

2. Kaplan, Sadock (2003) Psychological factors affecting medical condition and psychosomatic medicine Synopsis of Psychiatry 9: 829-831.

3. Kaplan, Sadock (2003) Late Adulthood (old age). Synopsis of Psychiatry 9: 53.

4. Shoja shafti S (2014) Prevalence of psychiatric morbidities inacute coronary heart disease. Cardiovascular Psychiatry and Neurology 3(1): $1-5$.

5. Haines AP, Imeson JD, Meade TW (1987) Phobic anxiety and ischemia heart disease. Br Med J 295(6593): 297-299.

6. Kaprio J, Koskenvuo M, Rita H (1987) Mortality after bereavement: A prospective study of 95,647 widowed persons. Am J Public Health 77(3): 283-287.

7. Booth Kewley S, Friedman HS (1987) Psychological predictors of heart disease: A quantitative review. Psychol Bull 101(3): 343-362. 
8. Rosenman RH, Brand RJ, Jenkins CD, Friedman M, Straus R, et al. (1975) Coronary heart disease in Western Collaborative Group Study: Final follow-up experience of 81/2 years. JAMA] 233( 8): 872-877.

9. Hecker MH, Chesney MA, Black GW, Frautschi N (1988) Coronary-prone behaviors in the Western Collaborative group study. Psychosom Med 50(2): 153-164.

10. Hearn MD, Murray DM, Luepker RV (1989) Hostility, coronary heart disease, and total mortality: a 33-year follow up study of university students. J Behav Med 12(2): 105-121.

11. Hamilton M (1960) A Rating Scale for Depression. J Neurol Neurosurg Psychiatry 23: 56-62.

12. Schulman JK, Muskin JK, Shapiro PA (2005) Psychiatry and cardiovascular disease. FOCUS 3(2): 208-224

13. Aben I, Verhey F, Strik J, Lousberg R, Lodder J, et al. (2003) A comparative study into the one year cumulative incidence of depression after stroke and myocardial infarction. J Neurol Neurosurg Psychiatry. 74(5): 581585.

14. Farisa R, Purcell H, Henein MY, Coats AJ (2002) Clinical depression is common and significantly associated with reduced survival in patients with non-ischaemic heart failure. Eur J Heart Fail 4(4): 541-551.

15. Moser DK, Dracup K (1996) Is anxiety early after myocardial infarction associated with subsequent ischemic and arrhythmic events. Psychosom Med. 58(5): 395-401.

\section{ISSN: 2574-1241}

DOI: 10.26717/BJSTR.2019.16.002842

Saeed Shoja Shafti MD. Biomed J Sci \& Tech Res

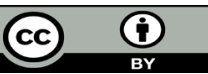

This work is licensed under Creative Commons Attribution 4.0 License

Submission Link: https://biomedres.us/submit-manuscript.php
16. Rudisch B, Nemeroff CB (2003) Epidemiology of comorbid coronary artery disease and depression. Biol Psychiatry 54(3): 227-240.

17. Rugulies R (2002) Depression as a predictor for coronary heart disease: A review and meta-analysis. Am J Prev Med 23(1): 51-61.

18. Gustad T, Laugsand E, Janszky I, Dalen H, Bjerkeset O (2014) Symptoms of anxiety and depression and risk of acute myocardial infarction: the HUNT 2 study. Eur Heart J 35(21): 1394-1403.

19. Lavie CJ, Milani RV (2006) Adverse psychological and coronary risk profiles in young patients with coronary artery disease and benefits of formal cardiac rehabilitation. Arch Intern Med 166(17): 1878-1883.

20. Milani RV, Lavie CJ, Mehra MR, Ventura HO (2011) Impact of exercise training and depression on survival in heart failure due to coronary heart disease. Am J Cardiol 107(1): 64-68.

21. Linden W, Stossel C, Maurice J (1996) Psychosocial interventions for patients with coronary artery disease: a meta-analysis. Arch Intern Med 156(7):745-752.

22. Johnston M, Foulkers J (1999) Impact on patients and partners of inpatient and extended cardiac counseling and rehabilitation: A controlled trial. Psychosom Med. 61(2): 225-233.

23. Braundwaid E (2001) Heart disease. 6(40): 1411.

24. Poshkov K, Fredric J, Dafao I (1999) Clinical cardiac rehabilitation. A cardiologist guide 2(1): 17.

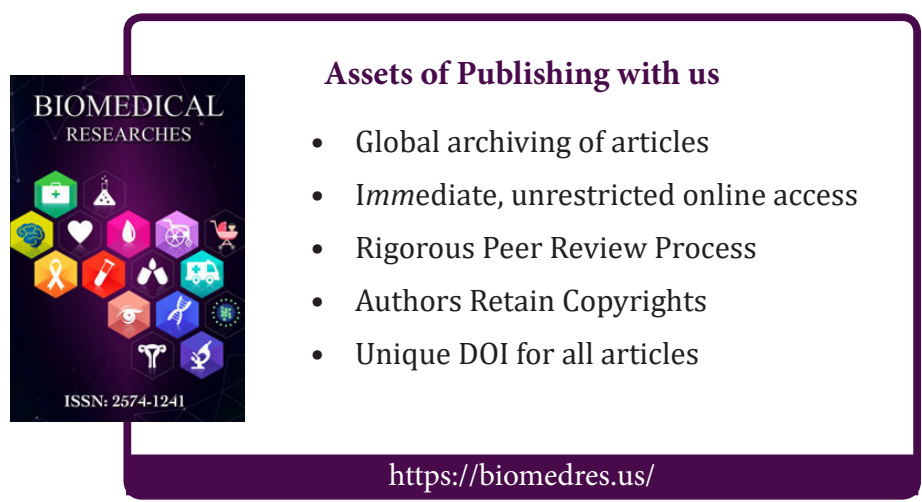

